\title{
American Board of Family Medicine (ABFM) Maintenance of Certification: Variations in Self- Assessment Modules Uptake within the 2006 Cohort
}

\author{
Andrew W. Bazemore, MD, MPH, Imam M. Xierali, PhD, Stephen M. Petterson, PhD, \\ Robert L. Phillips, Jr, MD, MSPH, FAAFP, Jason C.B. Rinaldo, PhD, \\ James C. Puffer, MD, and Larry A. Green, $M D$
}

Introduction: In its recent shift to a Maintenance of Certification for Family Physicians (MC-FP) paradigm, the American Board of Family Medicine provides diplomates completing 3 self-assessment modules (SAMs) in the first 3 years (or first stage of MC-FP) a pathway to extend their recertification cycle to 10 years provided additional requirements are met, versus a 7 -year cycle for "non-completers." We use geographic information systems to report on variations in SAM participation and completion in a single cohort of diplomates followed during their first stage of MC-FP to better understand the communities impacted, barriers to uptake, and urban-rural differences.

Methods: We merged data from 2006 MC-FP files, association workforce files, and the US Census and completed cross-sectional spatial, descriptive, and regression analyses of the uptake and timely completion of SAMs during a 3-year period. Specifically, we explored characteristics of diplomates who did not meet first-stage MC-FP requirements within 3 years versus those who did.

Results: The cohort comprised 10,812 participants who passed their certification or recertification examination in 2005, of which 30.5\% did not complete their MC-FP requirements by the end of 2008 . Noncompleters were more likely to be older $(P<.01)$, men $(P<.0001)$, and from areas of dense poverty $(P<.01)$ and underserved areas $(P<.05)$. There were no significant differences in MC-FP completion across the rural-urban continuum $(P=.7108)$.

Conclusions: More than two-thirds of eligible, certified family physicians completed stage-one MC-FP requirements. Concerns that technical aspects of the new MC-FP paradigm would leave parts of a widely distributed, poorly resourced primary care workforce disadvantaged may hold true for providers in some underserved areas, but differential completion among rural and remote physicians was not found. Understanding barriers to uptake is essential if the specialty boards are to meet their obligations to the public to promote quality of care through Maintenance of Certification for all physicians. $(\mathrm{J}$ Am Board Fam Med 2010;23:49-58.)

In 2000, the 24 member boards of the nonprofit American Board of Medical Specialties (ABMS) agreed to change their recertification programs from periodic recertification to one of continuous professional development, or Maintenance of Certification (MOC). ${ }^{1,2}$ This ongoing process was de-

This article was externally peer reviewed.

Submitted 1 May 2009; revised 29 June 2009; accepted 6 July 2009.

From The Robert Graham Center (AB, IX, SP, RLP), Washington, DC; American Board of Family Medicine (JCBR, JP), Lexington, KY; and Department of Family Medicine, University of Colorado (LAG), Aurora, CO.

Funding: none.

Conflict of interest: none declared.

Corresponding author: Andrew W. Bazemore, MD, MPH, The Robert Graham Center, 1350 Connecticut Ave, NW, Suite 201, Washington, DC 20036 (E-mail: abazemore@aafp.org). signed to help physicians stay abreast of advances in their fields, develop better practice systems, and demonstrate a commitment to lifelong learning. The ABMS, which covers the certification of $85 \%$ of US physicians, serves the public's interest through MOC by ensuring that physicians have and maintain the clinical judgment and skills on which high-quality care depends.

In the 4 decades since the creation of the specialty, Family Medicine has been a leader in protecting the public through the process of certifying of its graduates. To ensure the continued learning and competency of its diplomates, the American Board of Family Practice (now American Board of Family Medicine [ABFM]) in 1969 became the first specialty board to require mandatory recertification. More recently, and in response to both rapid 
advances in the body of medical knowledge and growing concerns about the performance of the US health care system, the ABFM adopted and implemented MOC for Family Physicians (MC-FP).

MOC includes 4 major components: demonstration of professional standing (part I), lifelong learning and self-assessment (part II), demonstrated cognitive expertise (part III), and practice performance assessment (part IV). ${ }^{1}$ The shift from recertification to MC-FP is being phased in by the ABFM from 2004 to 2010. During each of these 7 years, a new cohort enters MC-FP through successful certification or recertification by examination; they may opt to participate in the 4 parts of MC-FP starting on the first day of the next calendar year. To be eligible to extend their MC-FP period from 7 to 10 years, a diplomate must complete 2 self-assessment modules (SAMs) and one part IV module or 3 SAMs by the end of the third calendar year, or first stage, of MC-FP. Noncompleters face an abbreviated period of MC-FP. The current MC-FP phase-in is a period of intense evaluation and refinement for the ABFM, during which better understanding of diplomate uptake and participation in its various components is essential.

Because this is a voluntary process and a requirement for the physician wishing to remain certified in his or her discipline, much is to be learned about those that complete required elements of MC-FP such as SAMs ("completers") versus those who do not ("noncompleters"). Among the noncompleters, understanding differences between those who did not initiate participation in MC-FP through the completion of a single SAM ("nonparticipants") versus those who completed some but not all of the requirements for the extended period of MC-FP may further help to separate the behaviors of those who intentionally opt out from those who may have faced other barriers to full and successful MC-FP participation. MC-FP generally, and SAMs specifically, has been well-received in early evaluations, ${ }^{3}$ but concerns have been expressed about the additional burdens placed on busy clinicians-burdens which may be magnified in some settings. ${ }^{4,5}$

In this article we examine the demographic characteristics of the 2006 diplomate cohort who were successfully certified or recertified by examination in 2005. Recognizing the importance of spatial variation in MC-FP uptake and its potential impact on vulnerable geographies and populations, we also used geographic information systems (GIS) in a novel fashion to characterize the spatial distribution of the cohort and explore potential geographic barriers for MOC uptake in family medicine. We examine the group differences between completers, who successfully finished at least 3 SAMs by December 31, 2008, and noncompleters, who did not finish 3 SAMs by that date. We also demonstrate novel methods of evaluating MOC data to contribute to growing evidence of the power of GIS to inform primary care inquiry, planning, and policy. ${ }^{6-10}$

\section{Data}

The ABFM collects data about administrative records, addresses, demographic characteristics, and practice characteristics of diplomates who have either obtained or renewed their certification in Family Medicine. These diplomates' data were linked to American Academy of Family Physicians membership files and the American Medical Association masterfile in an attempt to geocode all diplomates to their principal office address to create a rich source of location and demographic data about the cohort. We achieved a 99\% geocoding match. The SAM data file contained detailed information about results from diplomates who have accessed SAMs through their respective physician portfolios at the ABFM web site. During the study period, modules became available on the following topics: asthma, coronary artery disease, depression, diabetes, health behavior, heart failure, hypertension, maternity care, pain management, and well child care.

We limited our study to the cohort of diplomates who passed the ABFM certification/recertification examination in 2005. Health professional shortage area designation geographies were obtained from the Health Resources and Services Administration web site ${ }^{11}$ and poverty data was taken from the Census Summary File 3. ${ }^{12}$

\section{Methods}

We used ESRI StreetMaps database ${ }^{13}$ to geocode ABFM data in ArcGIS version 9.3 (ESRI, Redlands, CA) and permitted the study of spatial-temporal variation of SAM uptake among the 2005 examination completers (2006 MC-FP cohort). These data were also linked to established measures 
of (1) rurality (the 2003 Rural Urban Continuum Codes $\left.[\text { RUCC] })^{14}\right)$; (2) rational primary care service delivery areas (the primary care service areas ${ }^{15}$ ); (3) federal metrics of primary care underservice (health professional shortage areas ${ }^{11}$ ); and (4) medically underserved areas/populations. ${ }^{11}$ The data were also linked to the 2000 Census Summary File $3 .^{12}$

To demonstrate novel approaches to characterizing the spatial dispersion of SAM uptakes, we used clustering methods to identify hotspots of noncompleters in selected metropolitan areas. We used descriptive statistics and simple bivariate analyses to examine the association between completion of requirements and physician age, sex, length of time in practice, and residency completion history. These included the use of Pearson's $\chi^{2}$ test to assess whether diplomates from different areas differed in the frequency of which they completed MC-FP requirements by the end of 2008 .

\section{Results}

A total of 10,812 diplomates passed their cognitive knowledge examination (part III of MC-FP) in 2005 and were therefore eligible for inclusion in the 2006 study cohort. Of these, 3302 (30.5\%) did not complete ("noncompleters") either the 2 SAMs and 1 part IV module or the 3 SAMs required by the end of 2008 that would have allowed them to remain eligible for extension of their MC-FP cycle to 10 years. Most of these diplomates $(n=2786$; $84 \%$ ) failed to complete a single SAM during this time period. Noncompleters were significantly more likely to be older ( 48.9 vs 45.8 years old), to have graduated residency $>7$ years before testing, and to work in a solo practice. These differences remained significant in multivariate models (available on request).

Small but significant $(P<.05)$ variation was detected between completers and noncompleters (Table 1) within 3 of the important geographies we considered-(1) shortage areas, (2) areas of dense poverty, and (3) rational primary care service areas-with high population to primary care physician ratios suggestive of primary care workforce inadequacy. Similar variation was detected between participants and nonparticipants in areas of dense poverty. No significant differences were detected among these same groups of diplomates serving rural areas. In multivariate analyses the population to primary care physician ratio and the shortage measures were not significant, primarily because of the strong association between these measures and area poverty.

As expected, because of known distribution patterns a decreasing number of cohort members in the increasingly rural strata of the RUCC existed (Table 2). However, a gradient of increasing or decreasing noncompletion or nonparticipation in SAMs as one moved along the continuum from more urban to more rural was not apparent, with completion rates remaining within a few percentage points of the mean (69\%) throughout. Among the small group that completed at least 2 SAMs, but not the 3 required modules (participants), variation along the RUCC did exist but no pattern was detectable in the direction of more rural or more urban.

Among 2006 diplomates who had completed at least one SAM, the most commonly completed were those for diabetes and hypertension, the 2 SAMs that were first released for completion ( $\mathrm{Ta}$ ble 3). Relative to averages for all SAMs completed, the well child care and maternity care SAMs were relatively more popular among younger and female diplomates whereas coronary artery disease, heart failure, and pain management were more popular among male participants. Heart failure and maternity care SAMs were also particularly popular among providers in areas of rurality, underservice (health professional shortage areas/medically underserved areas), and dense poverty.

Maps revealed interesting state- and countylevel variation, highlighting low completion rates in Maine, Wyoming, and the lower Mississippi River states (Figures 1 and 2). Areas with high densities of diplomates and hotspots of noncompleters were also used to demonstrate to ABFM staff and board members on the investigative team how GIS could be used to examine the spatial correlations between noncompletion and targeted geographies such as workforce shortage areas and areas of high poverty density (Figures 3 and 4).

\section{Discussion}

Rural MC-FP completion rates were consistent with urban rates whereas slightly lower uptake was seen in designated underserved and low-income areas. During this period of scrutiny and refinement for the MC-FP, it is critical to understand 
Table 1. Descriptive Statistics of 2006 Maintenance of Certification Cohort: Completers Versus Noncompleters of the Requirement to Complete 3 Self-Assessment Modules

\begin{tabular}{|c|c|c|c|c|c|c|}
\hline & \multicolumn{3}{|c|}{2006 Cohort } & \multicolumn{3}{|c|}{ Noncompleters } \\
\hline & $\begin{array}{l}\text { Completers } \\
(\mathrm{n}=7510)\end{array}$ & $\begin{array}{l}\text { Noncompleters } \\
\quad(\mathrm{n}=3302)\end{array}$ & $P$ & $\begin{array}{l}\text { Participants } \\
(\mathrm{n}=506)\end{array}$ & $\begin{array}{l}\text { Nonparticipants } \\
\quad(\mathrm{n}=2796)\end{array}$ & $P$ \\
\hline \multicolumn{7}{|l|}{ Demographic } \\
\hline Male & 59.36 & 70.17 & $<.01$ & 62.45 & 71.57 & $<.01$ \\
\hline Age & & & $<.01$ & & & \\
\hline$<35$ & 14.69 & 8.18 & & 9.68 & 7.90 & \\
\hline $35-44$ & 34.83 & 29.95 & & 30.04 & 29.94 & \\
\hline $45-54$ & 32.37 & 34.31 & & 33.79 & 34.41 & \\
\hline $55-64$ & 16.25 & 22.68 & & 23.52 & 22.53 & \\
\hline $65+$ & 1.86 & 4.88 & & 2.96 & 5.22 & \\
\hline $\begin{array}{l}\text { Family medicine residency within past } 7 \\
\text { years }\end{array}$ & 28.93 & 22.02 & $<.01$ & 24.70 & 21.53 & \\
\hline Solo practices & 9.45 & 16.66 & $<.01$ & 13.83 & 17.17 & \\
\hline \multicolumn{7}{|l|}{ Geographic } \\
\hline Rural & 17.47 & 18.53 & & 17.59 & 18.71 & \\
\hline Primary care HPSAs & 23.40 & 25.56 & $<.05$ & 22.92 & 26.04 & \\
\hline MUA/Ps & 21.24 & 22.96 & & 23.72 & 22.82 & \\
\hline HPSA or MUA & 32.70 & 35.61 & & 33.60 & 35.98 & \\
\hline $\begin{array}{l}\text { In census tract with }>20 \% \text { population } \\
\text { under } 200 \% \text { federal poverty line }\end{array}$ & 47.18 & 51.56 & $<.01$ & 46.25 & 52.61 & $<.01$ \\
\hline \multicolumn{7}{|l|}{$\begin{array}{l}\text { Primary care service area with population } \\
\text { to primary care physician ratio }\end{array}$} \\
\hline$<1500$ & 62.46 & 60.12 & $<.05$ & 61.86 & 59.80 & \\
\hline $1500-3000$ & 33.52 & 34.80 & & 33.20 & 35.09 & \\
\hline$>3000$ & 4.02 & 5.09 & & 4.94 & 5.11 & \\
\hline
\end{tabular}

Noncompleters refer to family physicians who did not complete 3 self-assessment modules by the end of the 3 rd year of the cycle; among the noncompleters, participants completed at least one self-assessment module but less than 3 . All data provided as percentages. HPSA, health professional shortage area; MUA/P, medically underserved areas/populations; MUA, medically underserved area.

variation in diplomate uptake and participation in its various components. Simultaneous attempts to reform MOC across the ABMS specialties, and even internationally, ${ }^{16}$ offer an opportunity for les- sons and insights from the largest primary care discipline to impact the entire medical workforce and the public it serves. This initial exploratory analysis is a starting point for testing data, linkages,

Table 2. 2006 Cohort Distribution across the Rural Urban Continuum

\begin{tabular}{lcccrrr}
\hline $\begin{array}{l}2003 \text { Rural-Urban Continuum } \\
\text { Code }\end{array}$ & Counties (n) & $\begin{array}{c}\text { Completers } \\
(\%)\end{array}$ & $\begin{array}{c}\text { Nonparticipants } \\
(\%)\end{array}$ & $\begin{array}{c}\text { Participants } \\
(\%)\end{array}$ & $\begin{array}{r}\text { Solo } \\
(\%)\end{array}$ & $\begin{array}{r}\text { Physicians in 2006 } \\
\text { Cohort (n) }\end{array}$ \\
\hline Not available & & 62.96 & 30.86 & 6.17 & 11.11 & 81 \\
1 (most urban) & 414 & 70.18 & 24.58 & 5.24 & 11.24 & 5000 \\
2 & 325 & 69.75 & 26.42 & 3.83 & 9.46 & 2483 \\
3 & 351 & 68.43 & 27.42 & 4.15 & 12.84 & 1324 \\
4 & 218 & 67.16 & 27.68 & 5.17 & 17.71 & 542 \\
5 & 105 & 70.77 & 26.92 & 2.31 & 12.69 & 260 \\
6 & 608 & 68.96 & 26.28 & 4.76 & 15.87 & 567 \\
7 & 450 & 66.84 & 27.85 & 5.31 & 11.14 & 377 \\
8 & 235 & 66.67 & 28.99 & 4.35 & 10.14 & 69 \\
9 (most rural) & 435 & 68.81 & 26.61 & 4.59 & 14.68 & 11.65 \\
Total & 3141 & 69.46 & 25.86 & 4.68 & 11.65 & 10,812 \\
\hline
\end{tabular}


Table 3. Demographic and Practice Characteristics by Type of Self-Assessment Module (SAM) Completed among the 2006 Cohort

\begin{tabular}{|c|c|c|c|c|c|c|c|}
\hline SAM Topic & $\begin{array}{l}\text { Diplomate } \\
\text { (n) }\end{array}$ & $\begin{array}{c}\text { Men } \\
(\%)\end{array}$ & $\begin{array}{c}\text { Rural } \\
(\%)\end{array}$ & $\begin{array}{c}\text { HPSA/MUA } \\
(\%)\end{array}$ & $\begin{array}{l}\text { FPL200 } \\
(\%)\end{array}$ & $\begin{array}{c}\text { PCSA }>3000: 1 \\
(\%)\end{array}$ & $\begin{array}{c}\text { Mean Age } \\
\text { (years) }\end{array}$ \\
\hline All & 10,812 & 62.66 & 17.80 & 33.59 & 48.54 & 4.35 & 46.7 \\
\hline Diabetes & 4988 & 59.64 & 17.90 & 32.90 & 48.10 & 4.27 & 46.2 \\
\hline Hypertension & 4533 & 61.13 & 15.62 & 31.94 & 46.39 & 3.88 & 46.2 \\
\hline Asthma & 3432 & 60.93 & 16.40 & 32.08 & 45.37 & 3.50 & 45.5 \\
\hline Coronary artery disease & 2592 & 71.80 & 20.95 & 33.95 & 49.92 & 4.28 & 47.0 \\
\hline Depression & 1973 & 51.44 & 15.21 & 31.73 & 44.80 & 4.00 & 45.7 \\
\hline Well child care & 1623 & 41.34 & 16.45 & 31.42 & 43.44 & 4.25 & 42.1 \\
\hline Pain management & 1177 & 67.80 & 18.10 & 33.05 & 47.41 & 4.08 & 46.9 \\
\hline Heart failure & 1118 & 68.34 & 24.69 & 37.75 & 54.38 & 5.10 & 47.4 \\
\hline Health behavior & 827 & 50.30 & 13.30 & 31.56 & 42.81 & 3.39 & 46.2 \\
\hline Maternity care & 710 & 39.15 & 23.38 & 39.44 & 53.52 & 4.23 & 42.2 \\
\hline No SAM taken & 2796 & 71.57 & 18.71 & 35.98 & 52.61 & 5.11 & 48.9 \\
\hline
\end{tabular}

HPSA, health professional shortage area; MUA, medically underserved area; FPL200, census tract with $>20 \%$ population under $200 \%$ federal poverty line; PCSA, primary care service area with population to physician ratios >3000:1.

Figure 1. Percentage of 2006 cohort of family physicians who were noncompleters, by state.

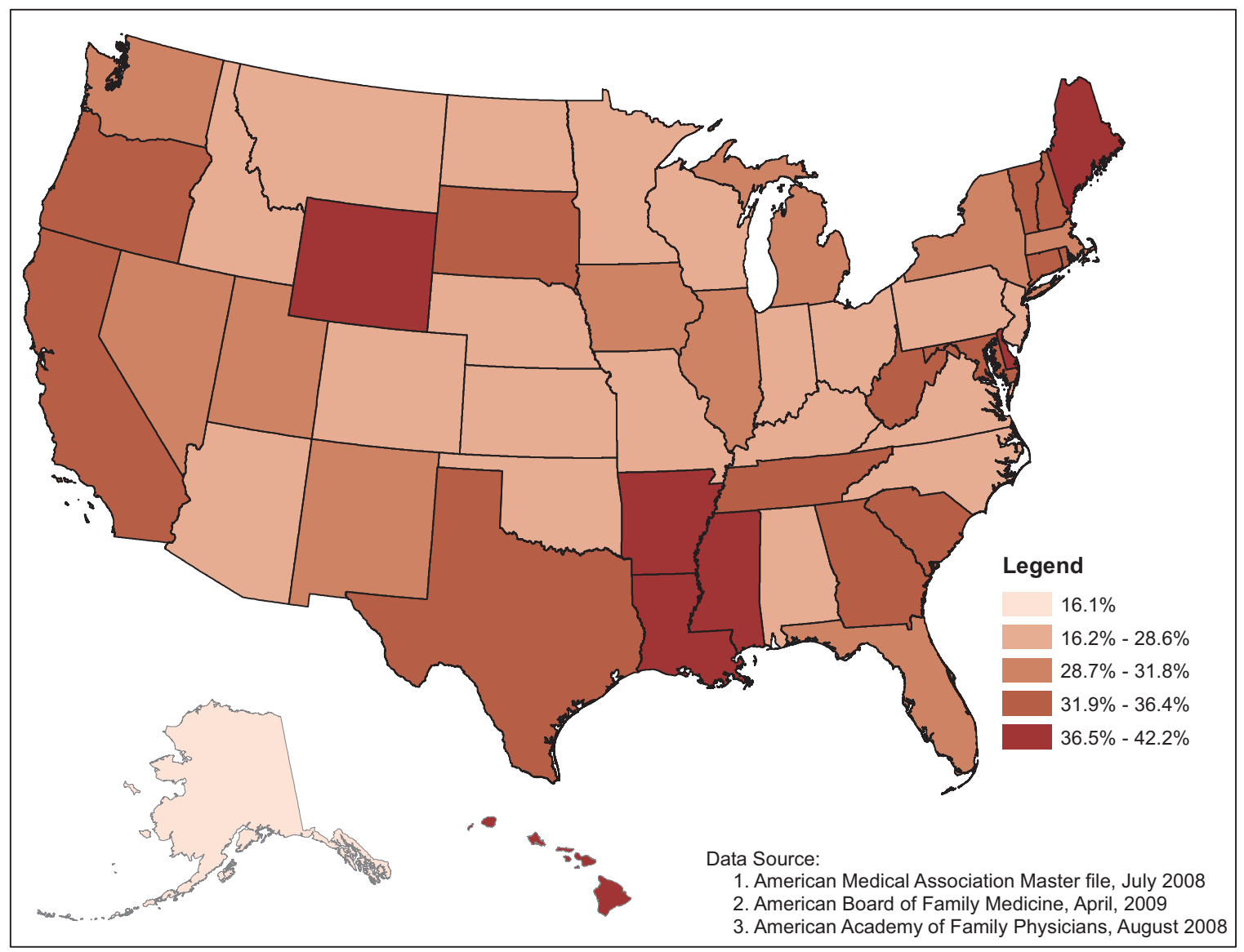


Figure 2. Percentage of 2006 cohort of family physicians who were noncompleters, by county.

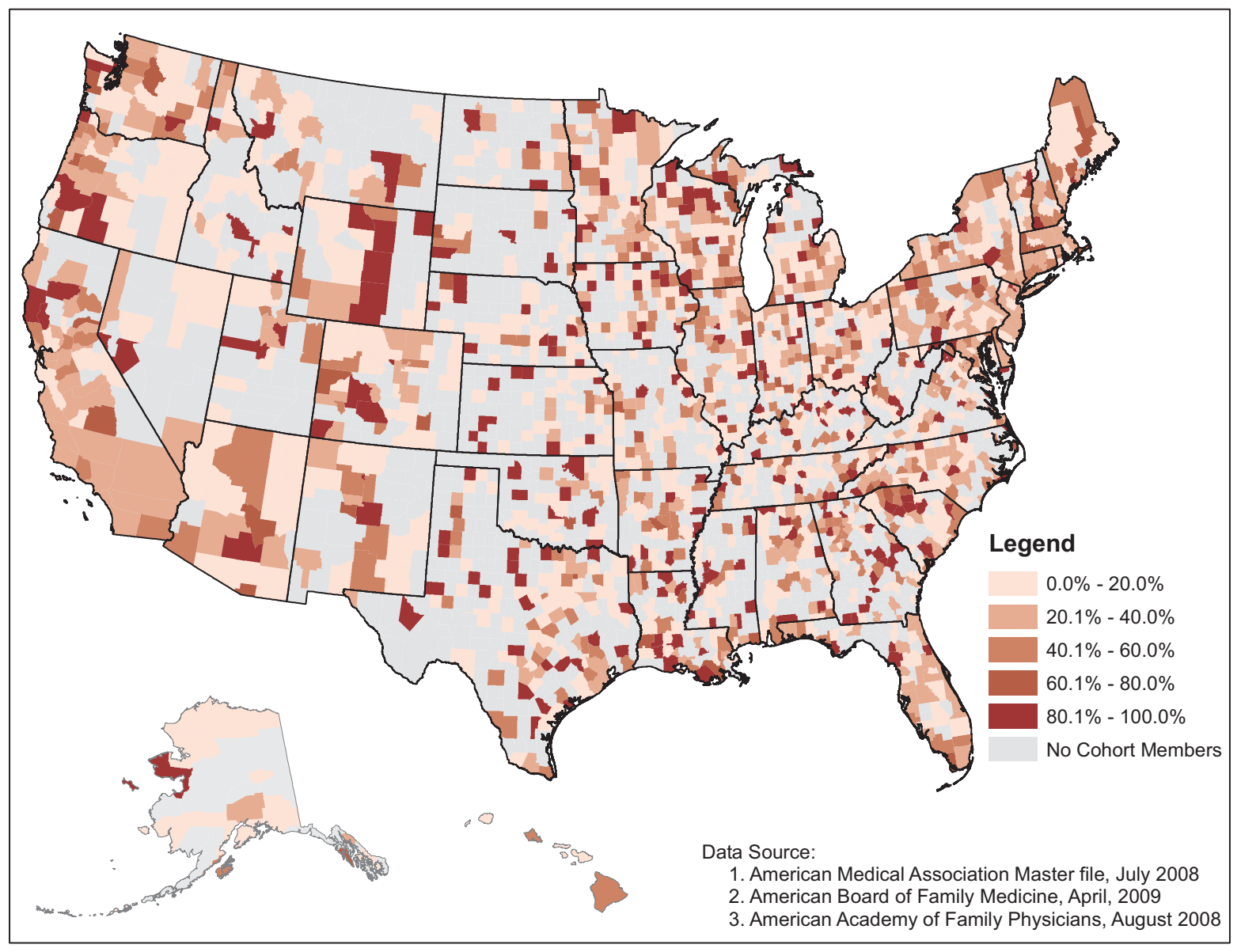

and, particularly, GIS applications necessary to understand the adoption and effects of MC-FP.

To our knowledge, GIS has not been used in evaluations of MOC to date, which leaves a gap in our knowledge about geographic dispersion of and the regional barriers to MOC uptake. At the study's outset we hypothesized that technical aspects of MC-FP would leave some parts of a widely distributed, poorly resourced primary care workforce disadvantaged, particularly in rural areas. Variation in information technology penetration in the United States, which ranked 25th worldwide with just over 50\% household broadband penetration in 2008, is considerable, with lower penetration more likely in rural areas. ${ }^{17}$ Smaller practice size, more limited availability of educational and continuing medical education resources, additional patient care, and additional financial burdens could all serve as barriers to adopting MC-FP in rural areas. ${ }^{18-20}$ However, despite this and other resource and educational disadvantages, differential completion among rural and remote physicians was not found.

This lack of variation in adopters across the rural-urban continuum merits further investigation but may be reassuring to the ABFM and other ABMS specialties that currently lag ABFM in their implementation of MOC. If MC-FP uptake is consistent even in rural areas, specialists clustered in urban areas with greater practice resources and information technology infrastructure might be expected to adopt at an equal or greater rate of success.

Furthermore, if this association was interpreted to mean that small and under-resourced rural physicians were nonetheless capable of pursuing the process of lifelong learning, it could also be an encouraging sign for quality improvement (QI) efforts in these areas in general, particularly if these same physicians stay on track and complete their part IV MC-FP practice performance assessment QI projects. Together, 
Figure 3. Percentage of 2006 cohort of Pennsylvania family physicians who were noncompleters, by county.

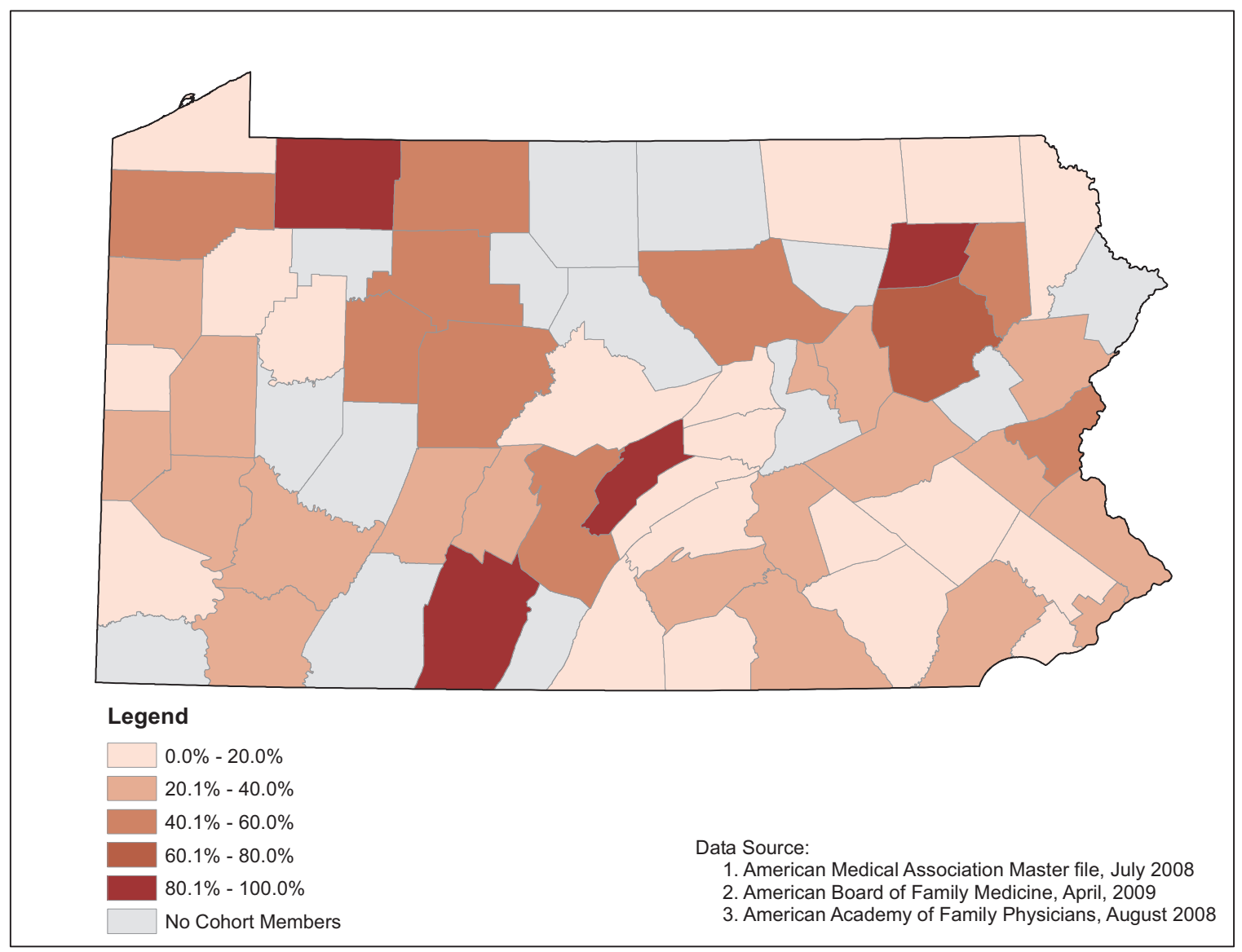

these might signal that small, rural outpatient centers are capable of undertaking additional QI efforts. This would not obviate the need to continue information technology and other infrastructure development efforts being launched by the new administration. However, it might signal the need for additional resources or facilitationsuch as those seen in the successful cooperative extension models used in US agriculture during the past century-to assist in office redesign in these areas, efforts that can help diplomates learn how to take lessons from MC-FP and further use them in practice.

On the other hand, noncompletion rates were slightly higher in some potentially vulnerable areas, namely in areas with the densest poverty. This may signal disparities in the readiness of this critical provider population to enter a new era of high-quality, information technology-driven care in a medical home to populations of significant concern to policymakers.
These findings are associations and should be interpreted with acknowledgment of the limitations of our analytical approach. We used and merged large secondary datasets in an attempt to geocode all diplomates to their principal office address while acknowledging that the American Medical Association masterfile is neither entirely accurate nor complete in capturing this location. In addition, through these files we could not assess the motivations or decision-making pathways of diplomates that led to completion or participation in MC-FP and SAM requirements. A range of motivations and circumstances might lead to noncompletion, including actual or anticipated retirement, procrastination, competing obligations, computer or technical incompetence, illiteracy or mere lack of support, change of specialty or professional status (eg, international medical graduates returning to their home country), or employment in settings where the financial and temporal incentives to maintain certification are low. To the latter, diplo- 
Figure 4. 2006 self-assessment module participation distribution and clustering in the Los Angeles metro area.

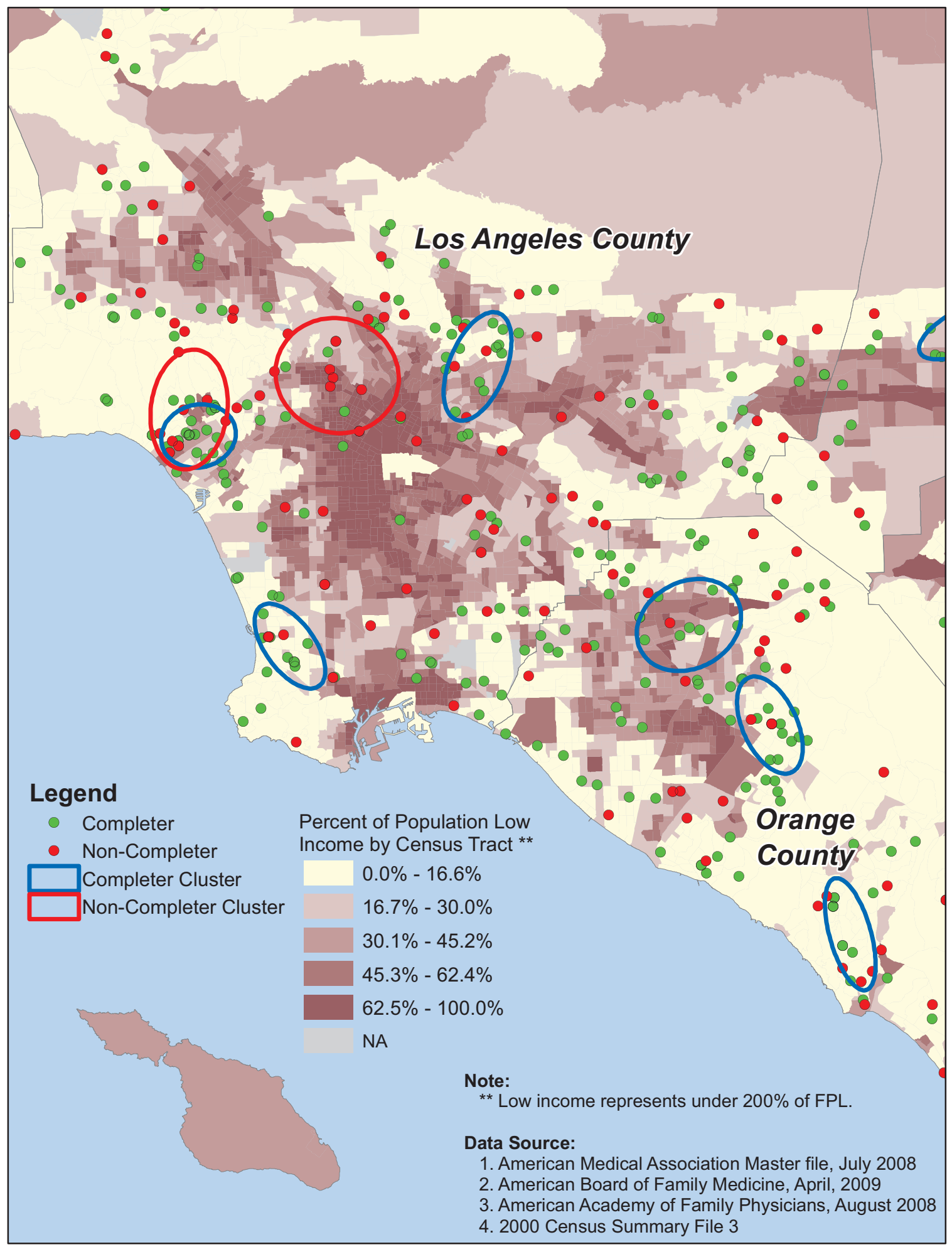

mates working in clinics and areas facing primary care staffing shortages, as has been reported in federally qualified health centers ${ }^{21}$ may be hired and retained irrespective of MOC status.
Our exploratory efforts to locate associations with MC-FP noncompletion should be followed with a search for additional predictors and multilevel regression and qualitative engagement of the 
noncompleters if we are to adequately probe the depths of how these differences might drive behavior and impact populations. Additional limitations related to geographic bias in the geocoding process should have been limited by the nearly $99 \%$ geocoding match between the ABFM and the American Medical Association/American Academy of Family Physicians files ${ }^{22,23}$; careful consideration of policyrelevant areal units and a tested consistency of findings across available units were undertaken to avoid potential error from the modifiable areal unit problem. $^{24}$

Perhaps the greatest contribution of this study is its novel use of GIS in the evaluation of MOC data. The capacity for granular analysis of diplomate behavior at the state or even community level through geocoding, spatial linkage, and analysis of large MOC and provider datasets has not been explored previously. Through these analyses, ABFM planners and stakeholders have been and will be able to understand the regional patterns of diplomate behavior like never before and will be able to adapt their implementation process accordingly. Variation in the types of SAMs taken across sex and geography variables also suggest variations in practice that can inform further MC-FP development. Options to identify population health needs or problems and target testing of physicians to improve those needs or problems may also exist. For instance, physicians in areas with high hospitalization rates for asthma could receive suggestions for asthma SAMs, and this connection of need to assessment could be tested for impact. Geospatial evaluation is potentially invaluable-not only to ABFM, but across the membership of ABMS.

Finally, the preponderance of sex- and agedriven preference for certain SAMs is consistent with what we know about sex- and age-driven practice patterns and panel composition, and gives some hint as to what we might expect from a demographic shift in family medicine providers. It will be worth exploring further how SAM-taking behavior impacts quality of care for all populations seen by specific groups of providers and is impacted by changes in scope of practice for certain segments of the family physician population.

We gratefully acknowledge support for this study from the American Board of Family Medicine Foundation and the assistance of Lisette Dunham in preparing this manuscript.

\section{References}

1. Miller SH. American Board of Medical Specialties and repositioning for excellence in lifelong learning: maintenance of certification. J Contin Educ Health Prof 2005;25:151-6.

2. American Board of Medical Specialties. Guide to physician specialties. Evanston, IL: Elsevier; 2009.

3. Hagen MD, Ivins DJ, Puffer JC, et al. Maintenance of certification for family physicians (MC-FP) self assessment modules (SAMs): the first year. J Am Board Fam Med 2006;19:398-403.

4. Edsall RL. Maintenance of certification. Fam Pract Manag 2005;12:11.

5. Welk S. MOC triggers resignation. Fam Pract Manag 2005;12:14.

6. Phillips RL, Bazemore A, Miyoshi TJ. Mapping tools for monitoring the safety net. Rockville, MD: Agency for Healthcare Research and Quality; 2003.

7. Bazemore AW, Phillips RL, Miyoshi TJ. Using geographic information systems to define health care access in an urban community health center network. ESRI Health GIS Conference Proceedings May 2003. Available at http://proceedings.esri.com/library/userconf/health03/papers/pap3037/p3037.pdf. Accessed 24 November 2009.

8. Farley ES Jr, Boisseau V, Froom J. An integrated medical record and data system for primary care. Part 5: implications of filing family folders by area of residence. J Fam Pract 1977;5:427-32.

9. Mullan F, Phillips RL, Kinman EL. Geographic retrofitting: a method of community definition in community-orientated primary care practices. Fam Med 2004;36:440-6.

10. Guagliardo M. Spatial accessibility of primary care: concepts, methods and challenges. Int $\mathrm{J}$ Health Geogr 2004;3:3.

11. US Department of Health and Human Services, Health Resources and Services Administration. Shortage designation: HPSAs, MUAs \& MUPs. Available at http://bhpr.hrsa.gov/shortage/. Accessed 2 November 2009.

12. US Census Bureau [home page]. Available at http:// www.census.gov/. Accessed 2 November 2009.

13. ESRI. ESRI StreetMap Premium: advanced geocoding, routing, and cartography. Overview. Available at http://www.esri.com/data/streetmap/index.html. Accessed 2 November 2009.

14. Vanderboom CP, Madigan EA. Federal definitions of rurality and the impact on nursing research. Res Nurs Health 2007;30:175-84.

15. Goodman DC, Chang CH, Bott D, Marth N, Wright-Slaughter P. ZCTA and PCSA data dictionary. 2003. Human Resources and Services Administration. Available at http://datawarehouse.hrsa.gov/ DataDownload/PCSA/HGDW_PCSA\%20DATA\% 20Dictionary.xls. Accessed November 24, 2009.

16. Silver I, Campbell C, Marlow B, Sargeant J. Self- 
assessment and continuing professional development: the Canadian perspective. J Contin Educ Health Prof 2008;28:25-31.

17. Point-Topic. World Broadband Statistics Report Q4 2008. Available at http://point-topic.com/content/ operatorsource/dslreports/world broadbandstatistics q4 2008.pdf. Accessed 24 November 2009.

18. Baldwin LM, Hart LG, West PA, Norris TE, Gore E, Schneeweiss R. Two decades of experience in the University of Washington Family Medicine Residency Network: practice differences between graduates in rural and urban locations. J Rural Health 1995;11:60-72.

19. Fryer GE Jr, Stine C, Vojir C, Miller M. Predictors and profiles of rural versus urban family practice. Fam Med 1997;29:115-8.

20. Backer EL, McIlvain HE, Paulman PM, Ramaekers
RC. The characteristics of successful family physicians in rural Nebraska: a qualitative study of physician interviews. J Rural Health 2006;22:189-91.

21. Rosenblatt RA, Andrilla HA, Curtin T, Hart LG. Shortages of medical personnel at community health centers: implications for planned expansion. JAMA 2006;295:1042-9.

22. Oliver MN, Matthews KA, Siadaty M, Hauck FR, Pickle LW. Geographic bias related to geocoding in epidemiologic studies. Int J Health Geogr 2005; 4:29.

23. Kravets N, Hadden WC. The accuracy of address coding and the effects of coding errors. Health Place 2007;13:293-8.

24. Unwin DJ. GIS spatial analysis and spatial statistics. Progress in Human Geography 1996;20:540-1. 